\title{
Preoperative virtual simulation for synchronous multiple primary lung cancers using three-dimensional computed tomography lung reconstruction: a case report
}

\author{
Weichun Wu', Yimin Wu' ${ }^{2}$ Gang Shen ${ }^{2}$ and Guofei Zhang ${ }^{2^{*}}$ (D)
}

\begin{abstract}
Background: As the positions and sizes of nodules in synchronous multiple primary lung cancer (SMPLC) patients differ, the development of surgical strategies to maximize long-term survival and preserved postoperative pulmonary function in SMPLC patients for whom surgical resection is an alternative strategy presents challenges.

Case presentation: We provide a case managed through video-assisted thoracoscopic surgery (VATS) resection using three-dimensional computed tomography lung reconstruction (3D-CTLR) to reconstruct lobes containing pulmonary nodules to preoperatively simulate and intraoperatively guide the extent and method of resection.

Conclusion: The successful attempt demonstrates a technically simplified, feasible alternative to preoperative plans utilizing less invasive VATS to manage SMPLC.
\end{abstract}

Keywords: Preoperative simulation, Synchronous multiple primary lung cancers, Three-dimensional computed tomography reconstruction

\section{Background}

Although there is no consensus as to diagnostic and therapeutic methods in synchronous multiple primary lung cancer (SMPLC) cases, surgical resection, especially with the mini-invasive technique of video-assisted thoracoscopic surgery (VATS), has been accepted as an alternative strategy for certain patients in this group [1]. However, controversies related to the method of resection still exist. To obtain a prognosis similar to that of solitary primary lung cancers (SPLCs), even those of a similar histologic subtype, and preserve postoperative

\footnotetext{
*Correspondence: 2312057@zju.edu.cn

${ }^{2}$ Department of Thoracic Surgery, The Second Affiliated Hospital of the

Zhejiang University School of Medicine, 88 Jiefang Road, Hangzhou 310009,

China

Full list of author information is available at the end of the article
}

pulmonary function, different surgical procedures based on the experience of the surgeons; the patient's age and cardiopulmonary function; and the size, quantity, and distribution of nodules have been individually adopted $[2,3]$. Three-dimensional computed tomography lung reconstruction (3D-CTLR) can accurately determine the relative positions of these nodules in the lobes. Here, we provide a typical clinical example to demonstrate a procedure to reconstruct lung lobes containing pulmonary nodules using 3D-CTLR, which depicts the relative relationship between nodules and lobes to simulate and intraoperatively guide the extent and method of surgical resection.

(c) The Author(s). 2021 Open Access This article is licensed under a Creative Commons Attribution 4.0 International License, which permits use, sharing, adaptation, distribution and reproduction in any medium or format, as long as you give appropriate credit to the original author(s) and the source, provide a link to the Creative Commons licence, and indicate if changes were made. The images or other third party material in this article are included in the article's Creative Commons licence, unless indicated otherwise in a credit line to the material. If material is not included in the article's Creative Commons licence and your intended use is not permitted by statutory regulation or exceeds the permitted use, you will need to obtain permission directly from the copyright holder. To view a copy of this licence, visit http://creativecommons.org/licenses/by/4.0/ The Creative Commons Public Domain Dedication waiver (http://creativecommons.org/publicdomain/zero/1.0/) applies to the data made available in this article, unless otherwise stated in a credit line to the data. 


\section{Case presentation}

A 58-year-old woman was admitted with eight groundglass opacity (GGO) lesions in the bilateral lobes at preoperative HRCT (four in the right upper lobe, two in the right lower lobe, and one each in the left upper and lower lobes, Fig. 1a-f). The largest nodule $(15 \mathrm{~mm})$ was a mixed GGO lesion at the apical segment of the right upper lobe, and the other pure GGO lesions were 3-6 $\mathrm{mm}$ in size. The patient was presumptively diagnosed with bilateral SMPLC. Her preoperative staging work-up indicated no signs of lymphadenopathy or distal metastasis. Additionally, the forced expiratory volume (FEV) 1 and FEV1/forced vital capacity (percentage predicted) in her preoperative pulmonary function tests were $2.38 \mathrm{~L}$ and 102.3 , respectively.

We used commercially available medical image processing software (Materialise Interactive Medical Image Control System [MIMICS], version 20.0, Materialise, Leuven, Belgium) to process the computed tomography (CT) data acquired from axial imaging and create an accurate $3 \mathrm{D}$, printable model. The 3D models demonstrate each of the lung lobes and display the reconstructed lungs and lung nodules in their real relative positions. Considering the relative position of the nodules in the lobes in the 3D-CTLR model in association with the size and number of nodules, we proceeded with uniportal VATS apical segmentectomy combined with wedge resection of the posterior segment of the right upper lobe and wedge resections of the right lower lobe (Fig. 2a-g).

Pathological examination confirmed six primary lung cancers (right upper lobe: one invasive adenocarcinoma (IAC), minimally invasive adenocarcinoma (MIA), and one adenocarcinoma in situ (AIS); right lower lobe: one MIA and one AIS). Chest CT 1 month after the operation showed that the right lung had good lung retention, and the FEV1 and FEV1/forced vital capacity (percentage predicted) in her postoperative pulmonary function test were $2.22 \mathrm{~L}$ and 94.4, respectively.

\section{Discussion and conclusion}

Surgical strategies for SMPLC present challenges. Each nodule's position and size differ; therefore, an
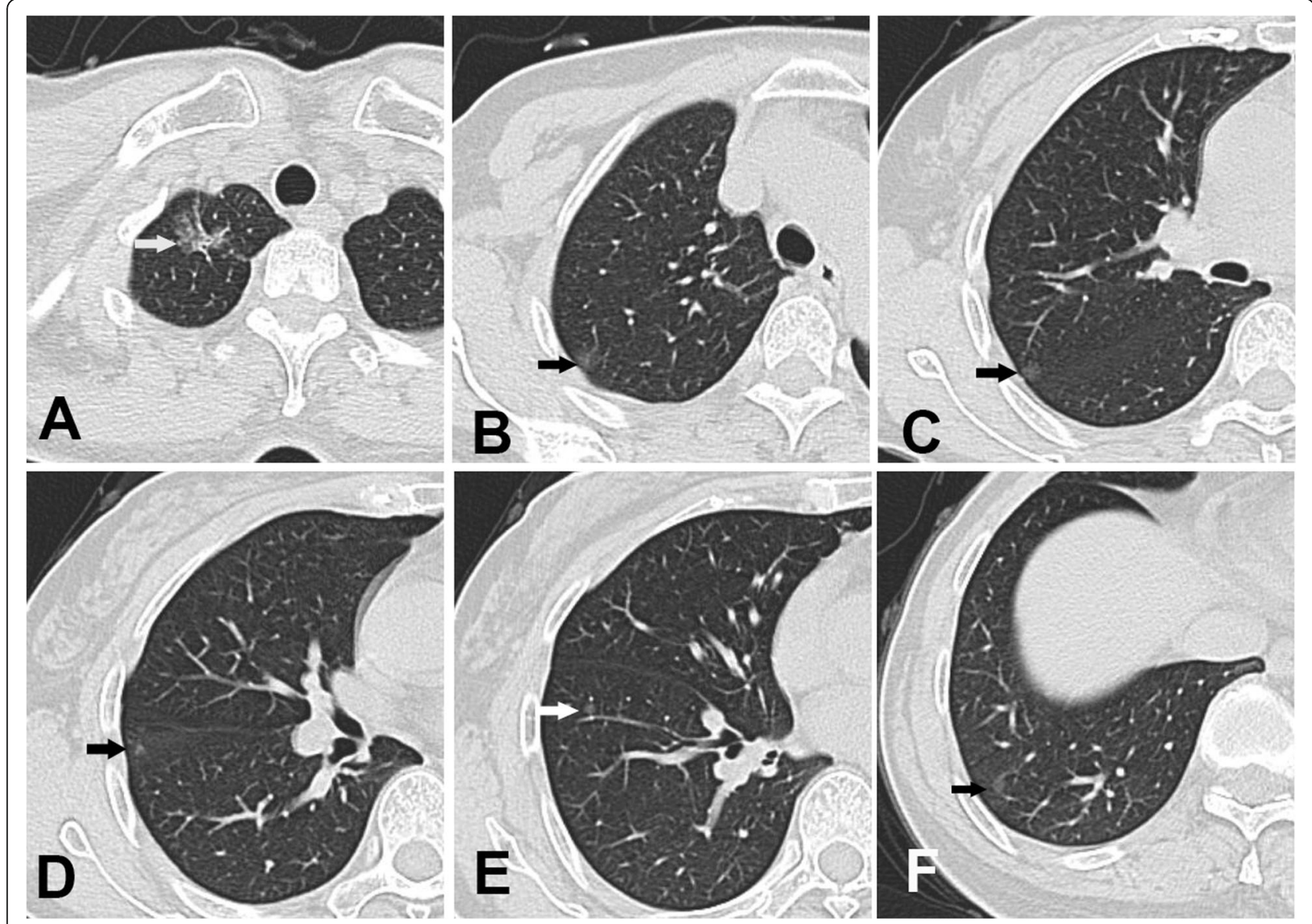

Fig. 1 High-resolution computed tomography images of patient 1 reveal six ground-glass opacity (GGO) lesions in the right lobe (arrows). a One nodule in the apical segment of the right upper lobe. $\mathbf{b}-\mathbf{d}$ Three nodules in the posterior segment of the right upper lobe. e, $\mathbf{f}$ Two lesions in the right lower lobe 
A
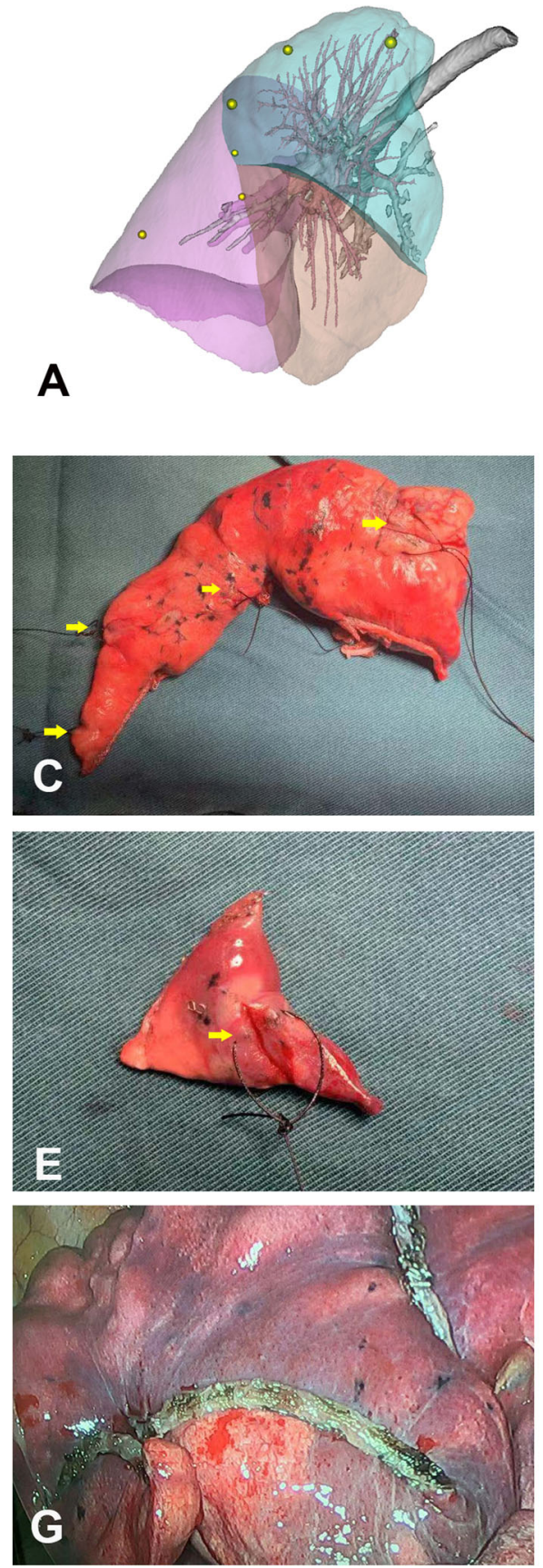
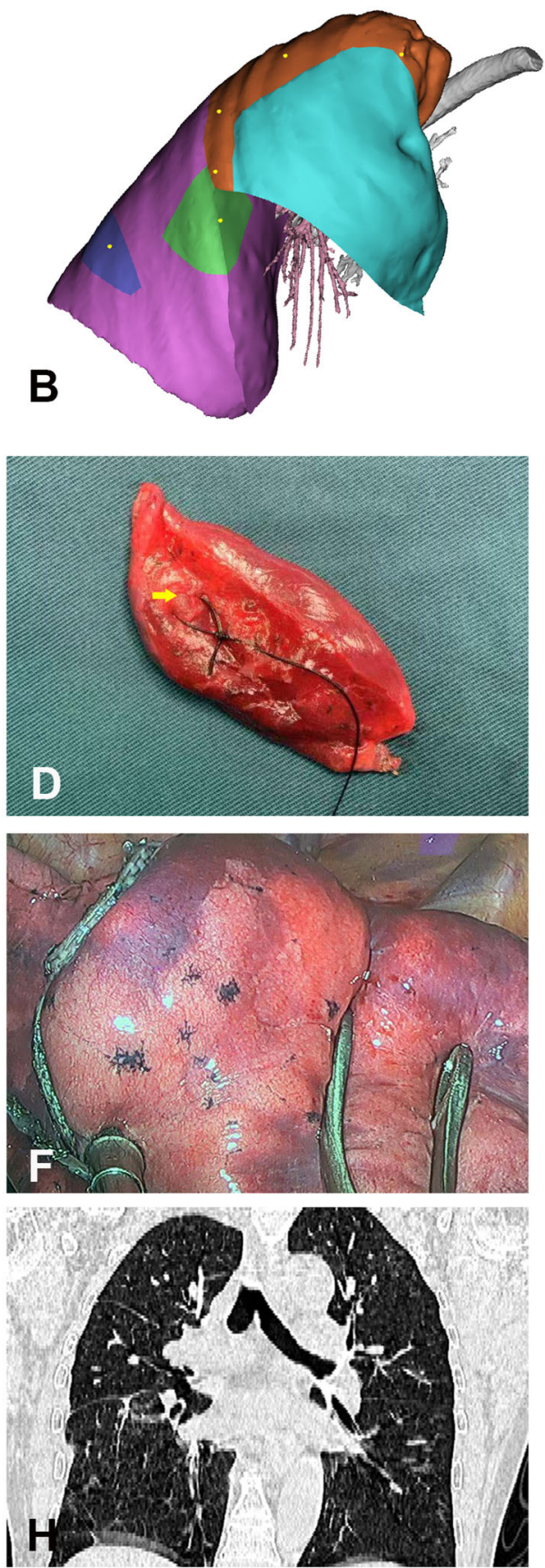

Fig. 2 Illustration of the surgical procedure used in the patient. a Three-dimensional computed tomography lung reconstruction of the right lung showing the relative positions of the nodules. $\mathbf{b}$ A schematic diagram of the resection of lesions in the right lobe. $\mathbf{c}$-e Resected specimens showing adequate surgical margins (arrows: $\mathbf{C}$, right upper lobe; D, E, right lower lobe). $\mathbf{f}$ Intraoperative view of the remaining right upper lobe after resection. $\mathbf{g}$ Intraoperative view of the remaining right lower lobe after resection. $\mathbf{h}$ Postoperative computed tomography images showing re-expansion of the right lobe with a large lung volume

individualized approach for the design of a surgical strategy for each patient with SMPLC is required. When the main lesion is removed, if surgical resection does not seriously affect pulmonary function, as many of the nodules in the same lobe or other lobes as possible are also surgically removed [4]. Therefore, it is very important to design an optimized surgical strategy prior to the operation. Herein, we provide a typical clinical example to demonstrate the preoperative planning procedure for the use of 3D-CTLR to reconstruct lobes containing nodules, virtual simulation, and intraoperative guidance of VATS resection. 
Surgical procedures for SMPLC are determined according to tumor size and location and cardiopulmonary function [5]. As pneumonectomy is associated with a high risk of postoperative respiratory failure and should be avoided whenever possible, sublobar resection for the first tumor, including wedge resection and segmentectomy under VATS, remains a good alternative; this is especially true for bilateral tumors, which usually require the sacrifice of less lung to preserve the feasibility and safety of contralateral resection [6]. There were four nodules in the right upper lobe of our patient. Without 3D-CTLR, our surgical plan may have included right upper lobectomy or apical posterior segmentectomy. We analyzed the relative positions of these nodules according to a 3D model, and we then chose sublobar resection, that is, apical segmentectomy with wedge resection of the posterior segment. This surgical strategy preserved the anterior segment and most of the posterior segment of the right upper lobe, which avoided right upper pneumonectomy. Therefore, we believe that the use of 3D-CTLR to plan the surgery, while ensuring nodular resection, can preserve lung tissue as much as possible. The latter is particularly important for patients with SMPLC. Of course, there are many factors and issues that need to be discussed, but through these this case, we wish to convey that for patients with SMPLC, preoperative 3D-CTLR can help us design a surgical strategy, that is, the extent and method of resection.

\author{
Abbreviations \\ SMPLC: Synchronous multiple primary lung cancer; VATS: Video-assisted \\ thoracoscopic surgery; 3D-CTLR: Three-dimensional computed tomography \\ lung reconstruction
}

\section{Acknowledgments}

Not applicable.

\section{Authors' contributions}

The conception and design of the study: Z.G., W.W. The acquisition of data: W.Y. All authors participated in analysis of the data. Drafting the article: W.W. All authors contributed to writing the manuscript and approved the final manuscript.

\section{Funding}

The authors have not received funding for the preparation of the present manuscript.

\section{Availability of data and materials}

The datasets used and/or analyzed during the current study are available from the corresponding author on reasonable request.

\section{Ethics approval and consent to participate}

The patient provided consent for the publication of her case including any individual details and images.

\section{Consent for publication}

The patient provided consent for the publication of her case including any individual details and images.

\section{Competing interests}

The authors declare that they have no conflicts of interest and competing interests.

\section{Author details}

'Department of Cardiothoracic Surgery, First People's Hospital of Yuhang District; Yuhang Branch of the Second Affiliated Hospital of the Zhejiang University School of Medicine, 369 Yingbin Road, Hangzhou 311100, China. ${ }^{2}$ Department of Thoracic Surgery, The Second Affiliated Hospital of the Zhejiang University School of Medicine, 88 Jiefang Road, Hangzhou 310009, China.

Received: 11 June 2020 Accepted: 26 December 2020

Published online: 07 January 2021

\section{References}

1. Komatsu H, Izumi N, Tsukioka T, Inoue H, Hara K, Miyamoto H, et al. Prognosis associated with synchronous or metachronous multiple primary malignancies in patients with completely resected non-small cell lung cancer. Surg Today. 2019;49(4):343-9.

2. Peng $Y$, Ren $W$, Wang $H$, Li M, Feng Z, Peng Z. Surgical treatment is an effective approach for patients with synchronous multiple primary lung cancers. J Cancer Res Ther. 2017;13(4):702-6.

3. She XW, Gu YB, Xu C, Li C, Ding C, Chen J, et al. Three-dimensional (3D)computed tomography bronchography and angiography combined with 3D-video-assisted thoracic surgery (VATS) versus conventional 2D-VATS anatomic pulmonary segmentectomy for the treatment of non-small cell lung cancer. Thorac Cancer. 2018;9(2):305-9.

4. Xiao F, Liu D, Guo Y, Shi B, Song Z, Tian Y, et al. Survival rate and prognostic factors of surgically resected clinically synchronous multiple primary nonsmall cell lung cancer and further differentiation from intrapulmonary metastasis. J Thorac Dis. 2017;9(4):990-1001.

5. Kocaturk Cl, Gunluoglu MZ, Cansever L, Demir A, Cinar U, Dincer SI, et al. Survival and prognostic factors in surgically resected synchronous multiple primary lung cancers. Eur J Cardiothorac Surg. 2011;39(2):160-6.

6. Liu M, He W, Yang J, Jiang G. Surgical treatment of synchronous multiple primary lung cancers: a retrospective analysis of 122 patients. J Thorac Dis. 2016;8(6):1197-204.

\section{Publisher's Note}

Springer Nature remains neutral with regard to jurisdictional claims in published maps and institutional affiliations.
Ready to submit your research? Choose BMC and benefit from:
- fast, convenient online submission
- thorough peer review by experienced researchers in your field
- rapid publication on acceptance
- support for research data, including large and complex data types
- gold Open Access which fosters wider collaboration and increased citations
- maximum visibility for your research: over $100 \mathrm{M}$ website views per year
At BMC, research is always in progress.
Learn more biomedcentral.com/submissions 